\title{
Comunicação e práticas de consumo, uma relação inovadora em termos de programa de pós-graduação
}

Ana Claudia Marigliani Bogner

Jornalista, especialista em Gestão da Comunicação pela Universidade de São Paulo. E-mail: anamarigliari@hotmail.com

Resumo: O Programa de Mestrado em Comunicação e Práticas de Consumo (PPGCOM) da Escola Superior de Propaganda e Marketing (ESPM) de São Paulo apresenta uma proposta inovadora, sendo o único no Brasil que se baseia nas relações do consumo e da comunicação. Este artigo visa analisar esse programa, a partir do processo de comunicação, para a divulgação de sua produção acadêmica, bem como para estabelecer sua consolidação no meio acadêmico. Abordamos, neste texto, temas como a história dos programas de pós- graduação no Brasil, além da história do PPGCOM e de suas atividades. Do ponto de vista teórico e metodológico, listamos, ainda, alguns autores e seus preceitos - que vão do campo científico às teorias de comunicação e de recepção e do consumo. Para chegar ao projeto de intervenção, elaboramos hipóteses e realizamos uma pesquisa com docentes, discentes e egressos, indicando por fim algumas ações a serem tomadas pelo PPGCOM-ESPM para consolidar seu programa no campo acadêmico.

Palavras-chave: Programa de Mestrado em Comunicação e Práticas de Consumo, ESPM, comunicação e consumo.
Abstract: The Masters Program in Communication and Consumer Practices (PPGCOM), School of Advertising and Marketing (ESPM), of São Paulo presents an innovative proposal, it is the only one in Brazil that is based on relations of consumption and communication. Therefore, this article aims to analyze it. To begin the process of communication process for the dissemination of academic production of PPGCOM - ESPM, as well as its consolidation in academia. Below, we discuss some topics as the history of post-graduate programs in Brazil, and the history of PPG$\mathrm{COM}$ and its activities. From the standpoint of theory and methodology, we list some authors and their precepts ranging field of science, theories of communication and reception and consumption, the conceptual point of view. To get to the intervention project, we developed hypotheses, we conducted a survey of faculty, students and graduates, and indicate some actions that should take ESPM-PPGCOM to consolidate its program in the academic field.

Keywords: Masters Program in Communication and Consumption Practices, ESPM, Communication and Consumer Affairs.

O curso de pós-graduação lato sensu "Gestão da Comunicação", inicialmente denominado "Gestão de Processos Comunicacionais", foi criado pelo Departamento de Comunicações e Artes da ECA-USP com o objetivo de estudar e aprofundar a reflexão a respeito das relações entre comunicação, cultura e 
comunicação \& educação • Ano XVII • número 2 • jul/dez 2012

educação, identificando os espaços profissionais abertos a essas relações e contribuindo para a formação de gestores de comunicação aptos a atuar nesses espaços. Entre os anos de 1993, quando foi criado, e 2011, em que foi reformulado para dar lugar a um curso lato sensu direcionado à Educomunicação, formou mais de 600 especialistas voltados ao trabalho ligado às áreas citadas. Este artigo traça o caminho de reflexão e aplicação dos conceitos discutidos no curso, em forma de Projeto de Intervenção, junto ao Programa de Mestrado em Comunicação e Práticas de Consumo (PPGCOM) da Escola Superior de Propaganda e Marketing (ESPM).

\section{A PÓS-GRADUAÇÃO NO BRASIL}

Em 2006, foi criado o Programa de Mestrado em Comunicação e Práticas de Consumo (PPGCOM) da Escola Superior de Propaganda e Marketing (ESPM), até hoje o único do tipo, no Brasil, que apresenta a relação da comunicação com as práticas de consumo. Porém, antes de abordarmos o PPGCOM-ESPM, é importante discorrer sobre a área da pós-graduação. Estudar a comunicação foi um processo que teve início nos Estados Unidos, entre 1920 e 1930, predominantemente pelo paradigma de Harold Lasswell, responsável por uma visão fragmentada e parcelar do processo de comunicação - que se mantém até hoje e se estrutura sobre os estudos do emissor, do canal, da mensagem e do receptor. Este paradigma visa, sobretudo, à compreensão do comportamento dos receptores para o controle e a manutenção do status quo.

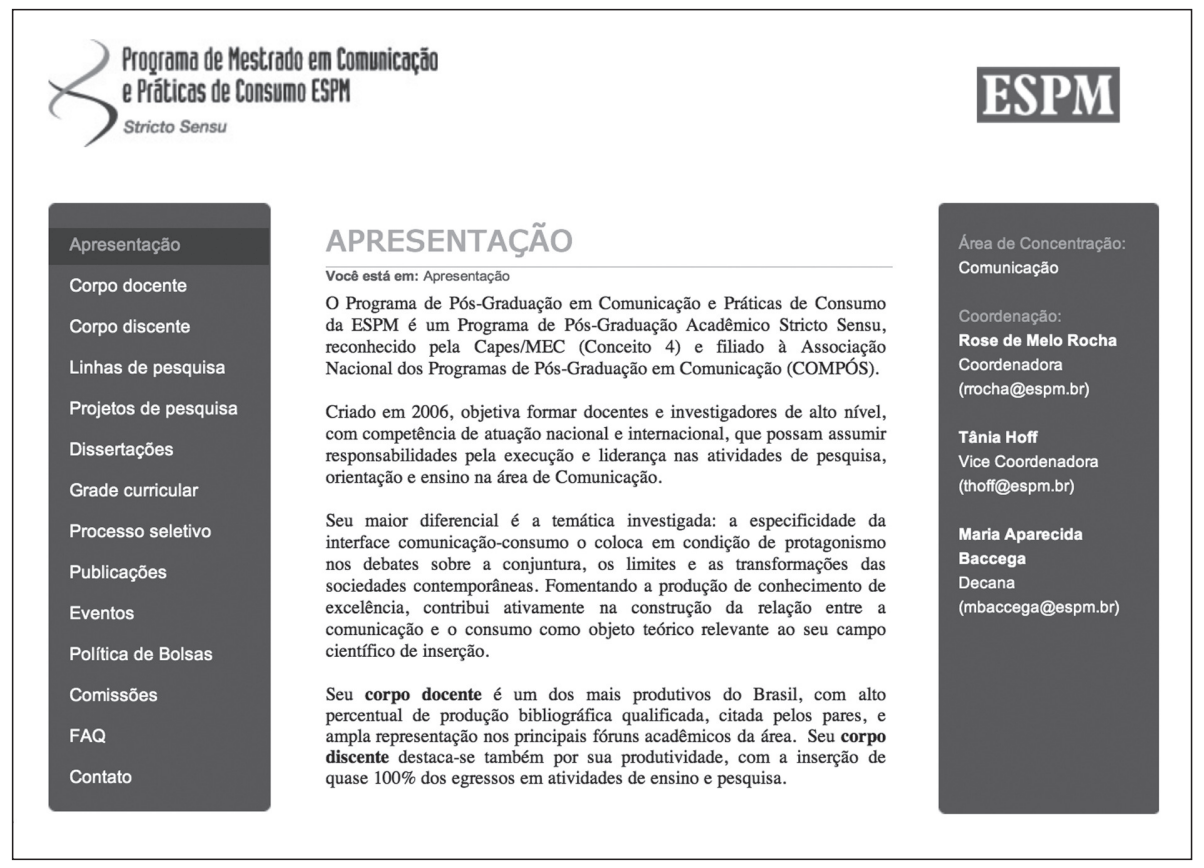


No Brasil, as autoridades governamentais começaram a estimular os programas de pós-graduação a partir dos anos 1960. O objetivo foi aumentar a formação de pesquisadores de diferentes áreas do conhecimento, implementando a produção científica e o desenvolvimento tecnológico. Nesse ano, por meio da Lei de Diretrizes e Bases da Educação (n. 4.024/61, art. 69), é que se organizou o sistema de pós-graduação no Brasil. Com o passar dos anos, os programas foram se modificando. Em 1992, a CAPES (Coordenação de Aperfeiçoamento de Pessoal de Nível Superior) passou a ser responsável pela expansão dos cursos de pós-graduação stricto sensu (mestrado e doutorado) em todo o país.

O primeiro programa público de mestrado em Comunicação no país data de 1972, ministrado pela Escola de Comunicações e Artes (ECA) da Universidade de São Paulo (USP). Hoje, conta com três áreas de concentração: Teoria e Pesquisa em Comunicação; Estudos dos Meios e da Produção Mediática; e Interfaces Sociais da Comunicação. São oito linhas de investigação, 42 professores/orientadores e 104 vagas por ano oferecidas a discentes. O primeiro programa de mestrado coordenado por uma instituição privada confessional, por sua vez, foi o da Pontifícia Universidade Católica de São Paulo (PUC-SP), criado em 1978 sob o nome de Mestrado em Comunicação e Semiótica. Após 22 anos, surgiu o primeiro programa de mestrado em comunicação elaborado por uma instituição considerada somente privada: o Mestrado em Ciências da Comunicação da Universidade do Vale dos Sinos (UNISINOS), criado em 1994, em São Leopoldo (RS). Já o PPGCOM-ESPM, também ministrado por uma instituição privada, começou a ministrar suas aulas em 2006. Conta com duas linhas de pesquisa: Impactos socioculturais da comunicação orientada para o mercado $^{1}$; e Estratégias de comunicação e produção de mensagens midiáticas voltadas às práticas de consumo. $\mathrm{O}$ curso, com duração de dois anos, possui em seu corpo docente 8 professores/orientadores e oferece a discentes 20 vagas por ano.

\section{A ESPM E O PPGCOM}

A ESPM foi criada, em 1951, pelo escritor e publicitário Rodolfo Lima Martensen. É considerada uma das escolas mais tradicionais do país, tendo recebido apoios importantes de nomes como Pietro Maria Bardi, fundador do Museu de Arte de São Paulo, e Assis Chateubriand, magnata do ramo das comunicações. Quando foi criada, recebeu o nome da Escola de Propaganda do Museu de Arte de São Paulo, oferecendo o curso de Comunicação Social com habilitação em Publicidade e Propaganda. Ao longo de sua trajetória, passou a oferecer novos cursos de graduação.

Em 2002, um grupo de professores doutores criou o Núcleo de Pesquisa em Comunicação em Práticas de Consumo, com o objetivo de planejar o PPGCOM-ESPM. Dois anos mais tarde, publicou um Caderno de Pesquisa com informações e resultados sobre a relação comunicação e consumo, divulgado para os outros programas de Pós-graduação de Comunicação. Assim foi elaborando
1. Em 2010, essa linha de pesquisa mudou de nome para "Impactos socioculturais da comunicação orientada para o mercado". 
comunicação \& educação • Ano XVII • número 2 • jul/dez 2012

o PPGCOM, aprovado pela CAPES em sua primeira proposta, em setembro de 2005. A primeira turma teve início em 2006, na unidade da ESPM, em São Paulo, onde ainda é oferecido. Em 2010, o PPGCOM conquistou nota 4 no Relatório Geral de Avaliação Trienal, promovido pela CAPES.

O processo seletivo para o curso é realizado por meio das seguintes etapas: divulgação de edital disponibilizado no site da ESPM; workshop gratuito que explica o que é o programa; análise dos pré-projetos de pesquisa e dos currículos Lattes dos candidatos; prova escrita; prova de idioma estrangeiro e entrevista com a equipe da linha de pesquisa selecionada.

São várias as atividades promovidas pelo PPGCOM-ESPM, entre elas: Grupo de Pesquisa em Comunicação e Práticas de Consumo, Simpósio Nacional de Comunicação e Práticas de Consumo, ciclo de palestras Conversações (descontinuado em 2011); e os Seminários "Pesquisa em comunicação e consumo" e "Intermestrandos em Comunicação" (direcionado aos mestrandos).

O programa estabelece ainda convênio com as universidades de Coimbra (Portugal) e Autônoma de Barcelona (Espanha). O Departamento do PPGCOM mantém comunicação constante com o Departamento de Marketing da ESPM, responsável pela comunicação interna da instituição e pela divulgação das atividades da escola junto ao mailing da instituição - composto por professores e alunos dos cursos de graduação, pós-graduação, programas de mestrados afiliados à Compós e interessados no programa -, além de oferecer suporte comunicacional aos eventos promovidos, elaborando materiais conforme demanda. Uma das ferramentas de comunicação utilizadas por esse Departamento são os murais espalhados por todo o campus - recurso que a instituição já comprovou ser falho. São utilizados também os Midiaplex (televisões LCD distribuídas pela escola), estratégia criada pela EXPM (Associação dos Ex-alunos da Escola Superior de Propaganda e Marketing).

A divulgação das produções acadêmicas é realizada pela Revista Comunicação, Mídia e Consumo, publicação quadrimestral que circula desde 2004 nas versões impressa e on-line. Outras ferramentas de comunicação utilizadas pela escola são seu site e o blog "Comunicação e Consumo", além de páginas nas redes sociais Facebook, Orkut e Twitter. A comunicação externa também ocorre por meio da agência de assessoria de imprensa da instituição, Tamer Comunicação Empresarial.

\section{OBJETIVOS DA PESOUISA}

Os objetivos da pesquisa foram agrupados em duas partes: o objetivo geral, que consiste em entender o processo de comunicação que se estabelece para a divulgação da produção acadêmica do PPGCOM - e em como a gestão de comunicação pode ajudar este programa a cumprir seus propósitos. E há também um objetivo específico, que visa identificar se o PPGCOM é reconhecido no meio acadêmico como um programa inovador e como uma ampliação 
das fronteiras do campo. Além disso, visa, ainda: entender como os docentes contribuem com o Grupo de Pesquisa, como os discentes e egressos avaliam o Simpósio, qual o interessse gerado pelas atividades do programa, e como essas atividades contribuem para pesquisas e dissertações. Outro objetivo da pesquisa é descobrir se as ferramentas utilizadas para a divulgação do programa (site, blog e revista) cumprem seus objetivos, ao menos internamente, e os motivos que levaram os alunos a escolherem o PPGCOM.

Enunciamos os problemas de pesquisa da seguinte forma: meios de comunicação, atividades extracurriculares do PPGCOM, atuação e produção dos discentes e egressos, e contribuição para a área.

\section{CONCEITOS TEÓRICOS E ASPECTOS METODOLÓGICOS}

Para construir o referencial teórico da pesquisa, estudamos diferentes autores, de forma a melhor compreender o campo da comunicação - destacando-se Bourdieu, que aborda as definições dos conceitos de campo científico, monopólio da autoridade científica e competência científica².

Para entendermos o PPGCOM-ESPM, consideramos a competição no campo, a função do pesquisador e a luta pela autoridade científica. Visando compreender as linhas de pesquisas propostas pelo programa de mestrado, analisamos ainda diferentes correntes teóricas como a da escola funcionalista, que esteve ligada a estudos desenvolvidos nos Estados Unidos e permanece, ainda hoje, como teoria hegemônica nos departamentos das universidades daquele país - entre eles o laboratório de pesquisa Socionomist Johan Bollen, da Universidade de Indiana, que estuda, por exemplo, o uso do Twitter como forma de verificar o humor social, vendo-o como algo padronizável e cujos resultados podem ser empregados com poder preditivo nos interesses das empresas no mercado consumidor.

A Teoria Crítica, criada por pesquisadores como Max Horkheimer, Theodor W. Adorno, Walter Benjamim, Jürgen Habermas, Herbert Marcuse e Erich Fromm $^{3}$, foi estudada. Também os estudos culturais constituíram-se numa visão interessante para compreender as pesquisas sobre recepção. "Pode-se finalmente considerar a abordagem cultural como fornecendo um quadro integrador para as pesquisas sobre recepção, com particular influência na América Latina"”.

Para compreender a importância de se ter um programa de mestrado que aborde o tema "Práticas de consumo", é preciso tratar do termo "consumo" do ponto de vista conceitual, sobretudo na perspectiva de Néstor García Canclini e da pesquisadora Maria Aparecida Baccega - uma das criadoras e professoras do PPGCOM-ESPM. Essa discussão se faz necessária para que possamos projetar estratégias de compreensão e de ação sobre a divulgação do referido programa de pós-graduação para a sociedade. Canclini aponta algumas significações para o termo "consumo": é um momento do ciclo de produção e reprodução social; é um lugar onde os conflitos entre classes, originados pela desigual participação na estrutura produtiva, ganham continuidade através da
2. BOURDIEU, P. Le champ scientifique. Acles de la Recherche en Sciences Sociales, n. 2/3, jun. 1976.

3. MATTELART, Armand: MATTELART, Michelle. História das Teorias da Comunicação. São Paulo: Loyola, 1998.

4. LOPES, M. I. V. Estratégias metodológicas da pesquisa de recepção. INTERCOM - Revista Brasileira de Comunicação, São Paulo, v. XVI, 2, p. 81, 1993. 
comunicação \& educação • Ano XVII • número 2 • jul/dez 2012

distribuição e apropriação dos bens ${ }^{5}$. Há ainda uma coerência entre os lugares em que membros de uma mesma classe (ou de uma fração de classe) se alimentam, estudam, moram e passam as férias - assim como naquilo que leem e desfrutam, na maneira como se informam e no que transmitem aos outros. Até mesmo em celebrações e rituais há o processo de compra - em que se utilizam objetos materiais para estabelecer o sentido e as práticas que os encerram. Para Maria Aparecida Baccega, "consumo não é apenas consumismo, mercadorização do próprio consumo. Ele é indispensável à existência de qualquer sociedade" .

\section{RESULTADOS DA PESQUISA}

Elaboramos hipóteses segmentadas em duas formas: central e secundária. Na hipótese central, partimos do pressuposto de que os docentes, discentes e egressos do PPGCOM têm contribuído para a produção acadêmica do programa por meio da publicação de artigos, capítulos de livros, livros e até mesmo de dissertações - o que, consequentemente, ajudaria a disseminar e elevar o prestígio do PPGCOM na área acadêmica da Comunicação. Entre as hipóteses secundárias estariam as atividades que o programa propõe a seus discentes, egressos e docentes - como a revista Comunicaşão, Mídia e Consumo e o Simpósio Comunicação e Práticas de Consumo, além do Grupo de Pesquisa, site, blog e redes sociais do PPGCOM. Inclui-se também como hipótese a produção acadêmica do PPGCOM, composta por dissertações e artigos com temas inéditos, que geram interessse junto aos meios de comunicação (internet, jornal, TV) e na área acadêmica da Comunicação.

$\mathrm{Na}$ pesquisa, foram utilizadas técnicas de amostragem para confirmar ou derrubar as hipóteses elaboradas. Foi elaborado um questionário qualitativo direcionado aos discentes do primeiro ano, formado por perguntas objetivas e questões fechadas de múltipla escolha, abertas ou mistas. O mesmo questionário foi aplicado junto aos discentes do segundo ano, porém com ênfase nas atividades extracurriculares do PPGCOM e na produção acadêmica. Para os egressos do curso, foram incluídas questões sobre os eventos, a produção acadêmica e as dificuldades encontradas durante o programa. As docentes do programa, a profa. dra. Gisela Castro, a profa. dra. Márcia Perecin Tondato e a profa. dra.

5. CANCLINI, Nestor García. Consumidores e cidadãos. Rio de Janeiro: UFRJ, 1995.

6. BACCEGA, M. A. Comunicação/educação: relações com o consumo. Importância para a constituição da cidadania. Revista Comunicação, Mídia e Consumo, São Paulo, v. 7, n. 19, p. 52, 2010
Maria Aparecida Baccega, também foram selecionadas para responder à pesquisa - incluindo questões sobre como avaliariam o PPGCOM e as contribuições dele para a área da Comunicação, além das contribuições pessoais de cada uma em termos de pesquisa. Na entrevista com a vice-coordenadora do PPGCOM, a profa. dra. Tânia Hoff, foram abordadas as contribuições do programa para o campo da Comunicação; a importância de se ter um programa de mestrado na área de Comunicação e Práticas de Consumo: o significado do conceito de consumo e como ele se estabelece com a comunicação: e, por fim, quais os desafios atuais desses campos e o que o PPGCOM faz para enfrentá-los. Fizemos 
ainda uma pesquisa na internet sobre o PPGCOM e analisamos o resultado da Avaliação Trienal da CAPES.

\section{RESULTADOS EXPRESSIVOS}

Observamos que as docentes e a vice-coordenadora sabem da importância que o PPGCOM apresenta para a sociedade, embora reconheçam, também, a dificuldade das pessoas em entenderem a relação entre comunicação e consumo - uma relação inovadora, cujo estudo e compreensão são imprescindíveis, especialmente em um país emergente como o Brasil, mas que ainda enfrenta dificuldades para ser reconhecida. Pode-se afirmar que, apesar de recente, o PPGCOM "circula" com suas mensagens, seja por meio dos eventos que promove, dos eventos de que participa ou das produções acadêmicas nos meios de comunicação específicos da área.

A pesquisa junto aos discentes e egressos contou com 21 participantes (sete ex-alunos, sete alunos do $1^{\circ}$ ano e sete alunos do $2^{\circ}$ ano). A maioria dos entrevistados foi de mulheres entre 31 e 50 anos, sendo nove estudantes da área de Comunicação (observamos que os discentes e egressos do curso vêm, em sua maioria, da área de Comunicação). Muitos entrevistados, porém, vieram de áreas como Engenharia, Psicologia, Moda e Agronomia, o que significa que o PPGCOM está alcançando outros campos científicos. Os discentes e egressos também são responsáveis por disseminar o programa, difundir suas ideias e conceitos.

Os resultados apontam ainda que, dos sete entrevistados, apenas uma aluna do $2^{\circ}$ ano do curso, efetivamente, produziu um artigo. Entre os egressos do curso, foi apontada a dificuldade em escrever textos acadêmicos, assim como falhas em relação ao conceito de uso dos meios de comunicação digitais. De acordo com a pesquisa, o site do PPGCOM, embora receba muitos acessos, precisa ser melhorado: informações como notícias, convites para eventos e chamadas para a inserção de artigos em revistas e seminários, que deveriam constar no site, estão no blog. Também a Comissão da Avaliação Trienal da CAPES formulou, em 2010, uma sugestão para o site que até o momento não foi adotada: a inserção de uma explicação detalhada acerca das políticas de atribuição de bolsas de agências de fomento e do PPGCOM, em que constem os critérios de distribuição e a descrição do funcionamento da comissão de bolsas. Os entrevistados também fizeram sugestões relativas às redes sociais (Twitter, Orkut e Facebook), que, segundo eles, precisam ser mais divulgadas. O pedido de criação de fóruns para discussão, registrado durante a pesquisa, por exemplo, pode ser atendido por meio dessas redes. Já a revista $C M C$ foi muito bem classificada pelos entrevistados, que destacaram a qualidade dos artigos escritos por autores interessantes e renomados. Embora o Projeto de Intervenção aponte ainda itens a melhorar, pode-se dizer que o PPGCOM caminha para a sua consolidação. 
comunicação \& educação • Ano XVII • número 2 • jul/dez 2012

\section{PROJETO DE INTERVENÇÃO}

O gestor tem um papel importante no projeto, já que deve ter a visão completa da situação a ser analisada. Dessa forma, procuramos evidenciar aqui todos os pontos positivos e negativos do objeto, sem desprezar qualquer dado ou manifestação. A visão inicial a respeito do PPGCOM foi modificada ao longo do projeto: atualmente, vemos o programa como uma iniciativa que vem construindo sua reputação por meio de sua expansão.

Entre as ações sugeridas pelo Projeto de Intervenção, está o uso mais eficaz dos meios de comunicação disponibilizados pela própria ESPM. Para ser veiculado nos murais da escola, indicamos um boletim mensal contendo informações sobre as atividades mensais do PPGCOM e anúncios de eventos. As mesmas informações podem ser divulgadas pelos canais digitais de comunicação, como o site, o blog e as redes sociais, assim como pelo Midiaplex - garantindo que os graduandos tenham interesse em desvendar o novo campo. A divulgação dos principais congressos, seminários, simpósios e demais eventos acompanhados de suas respectivas datas facilitará aos discentes a organização para escrever e encaminhar trabalhos. Da mesma forma, as chamadas para publicações em revistas da área de Comunicação podem ser divulgadas em todos os canais de comunicação já descritos, e não apenas no blog. Seria interessante ainda que, ao final de cada disciplina, uma banca composta por professores pudesse escolher o melhor artigo da turma e encaminhá-lo para revistas acadêmicas, seminários e congressos. A realização de workshops para a produção de artigos, envolvendo desde a escolha do tema, a abordagem e o desenvolvimento desta competência, também poderia incentivar a escrita e publicação de textos pelos alunos desde o $1^{\circ}$ ano do curso, combatendo as dificuldades apontadas nessa atividade pelos entrevistados.

Devido ao reconhecimento da ESPM no mercado, acreditamos que o PPGCOM não encontrará dificuldades em elaborar parcerias com instituições de grande porte como o Serviço Social do Comércio (SESC), Instituto Itaú Cultural, com outros Programas de Mestrado em Comunicação e até mesmo com organizações não governamentais que trabalham na área do consumo inteligente, como Instituto Akatu e Terracycle. Essas parcerias poderiam ser estabelecidas por ocasião de seu simpósio ou até mesmo na criação de outros eventos. Outra sugestão consiste em, a cada semestre, trazer docentes de universidades estrangeiras para palestrar não apenas para os alunos do curso, mas em eventos abertos também a outros programas da área de Comunicação.

Sugerimos ainda que o material de divulgação do PPGCOM-ESPM traga informações mais detalhadas sobre o significado da relação entre comunicação e consumo. As palestras poderiam se estruturar sobre a investigação inicial de como os próprios participantes definem a palavra consumo, esclarecendo em seguida seu significado e explicando como o PPGCOM vem estudando essa nova e importante área no Brasil. Na área de mídias digitais, sugere-se a reformulação 
do site e do blog, assim como a divulgação das atividades do curso para os discentes e egressos por meio de redes sociais (Twitter, Orkut, Facebook).

Destacamos também a importância da imprensa na divulgação de toda e qualquer notícia referente ao PPGCOM. É ideal, dessa forma, que as pesquisas produzidas pelo programa sejam transformadas em linguagem passível de divulgação em jornais, revistas, rádio, televisão e internet, assim como entre "blogueiros", que, embora não sejam necessariamente jornalistas, têm angariado mais e mais leitores por meio de divulgação, comentário e opinião sobre assuntos diversos.

Sugerimos que a produção científica produzida pelo PPGCOM seja apresentada no Seminário Pesquisa em Comunicação e Consumo. É ideal ainda que o PPGCOM elabore um mailing para entrar em contato com os departamentos de outras instituições de Ensino Superior e, assim, possa encaminhar a elas mensalmente um boletim. Por meio desses contatos, o PPGCOM poderá iniciar um diálogo com as demais instituições de Ensino Superior, promovendo palestras para seus alunos de graduação, especialização e mestrado, sempre no sentido de disseminar a importância das relações entre Comunicação e Práticas de Consumo. Como sugestão final, está o estímulo à interação, à competição e, principalmente, ao aprendizado, difundindo a relação da Comunicação e Práticas de Consumo por meio de um concurso cultural.

\section{REFERÊNCIAS BIBLIOGRÁFICAS}

APPADURAI, Arjun (ed.). La Visa social de las cosas. México: Grijalbo, 1991.

BACCEGA, Maria Aparecida. Comunicação/educação: relações com o consumo. Importância para a constituição da cidadania. Revista Comunicação, Mídia e Consumo, São Paulo, v. 7, n. 19, 2010.

BOSI, Ecléa. A opinião e o estereótipo. Revista Contexto, n. 2, mar. 1977.

BOURDIEU, Pierre. Le champ scientifique. Acles de la Recherche en Sciences Sociales, n. 2/3, jun. 1976.

CANCLINI, Nestor García. Consumidores e cidadãos. Rio de Janeiro: Ed. UFRJ, 1995.

CAPES. História do Programa Nacional de Pós-graduação. Brasília, 1975-1982. Disponível em: <http://www.capes.gov.br/images/stories/download/editais/I_ PNPG.pdf>. Acesso em: 28 abr. 2011.

Avanço da Pós-graduação no Brasil. Brasília, 2009. Disponível em: $<$ http:/ / www.capes.gov.br/servicos/sala-de-imprensa/36-noticias/3364-mudaro-mapa-das-assimetrias-regionais-e-um-desafio-da-pos-graduacao $>$. Acesso em: 28 abr. 2011.

CASTELLS, Manuel. La Cuestión urbana. México: Siglo XXI, 1974. 
comunicação \& educação • Ano XVII • número 2 • jul/dez 2012

COSTA, Maria Cristina Castilho. Ficção, comunicação e mídias. São Paulo: Senac, 2002.

ESCOSTEGUY, Ana Carolina: Estudos Culturais: uma Introdução. In: DA SILVA, Tomaz Tadeu (org.). O que é, afinal, Estudos Culturais? Belo Horizonte: Autêntica, 1999.

FIGARO, Roseli. Atividade de comunicação e trabalho. Provence, 2007.

GOMES, Maria Mota Itania; PINTO, Julio; ESCOSTEGUY, Ana Carolina. Antecedentes, tendências e perspectivas da pós-graduação em Comunicação. In: Panorama da Comunicação e das telecomunicações no Brasil. Brasília: Ipea, v. 2, 2010.

HALL, Stuart. In: LIV, Sovik (org.). Da diáspora. Identidade e mediações culturais. Belo Horizonte/Brasília: Editora UFMG/Unesco, 2003.

KUHN, Thomas. The Structure of Scientific Revolutions. Chicago: The University of Chicago Press, 1962.

LOPES, Maria Immacolata Vassalo de. O campo da comunicação: sua constituição, desafios e dilemas. Revista FAMECOS, Porto Alegre (RS), n. 30, ago. 2006.

- Estratégias metodológicas da pesquisa de recepção. INTERCOM Revista Brasileira de Comunicação, São Paulo, v. XVI, 2, 1993.

MATTELART, Armand; MATTELART, Michelle. História das teorias da comunicação. São Paulo: Loyola, 1998.

MORIN, Edgar. A cabeça bem feita. Rio de Janeiro: Bertrand, 2000.

MOTTER, Maria de Lourdes. Cotidiano e linguagem. In: BACCEGA, M. A. (org.). Gestão de processos comunicacionais. São Paulo: Atlas, 2002.

ORTIZ, Renato (org.). A sociologia de Pierre Bourdieu. São Paulo: Ática, 1983.

ROMANCINI, Richard. O campo científico da comunicação no Brasil: institucionalização e capital científico. (Tese de doutorado em Ciências da Comunicação). São Paulo: Universidade de São Paulo - Escola de Comunicação e Arte, 2006, $276 \mathrm{f}$.

RÜDIGER, Francisco. Comunicação e teoria social moderna. Porto Alegre: Fênix, 1995 . 


\title{
Para além da forma, trabalhar o conteúdo
}

\author{
Juliana Winkel \\ Jornalista, especialista em Gestão da Comunicação, mestranda em Cîencias da Comunicação $e$ \\ editora executiva da revista Comunicação Ẽ Educação. \\ E-mail: juli.santos@usp.br
}

\begin{abstract}
Resumo: Gianna Cappello, presidente da Associazione Italiana per l'Educazione ai Media e alla Comunicazione (MED), fala sobre o aumento geral do interesse pela Media Education no mundo - e sobre as prioridades que os profissionais envolvidos com os campos da Comunicação e da Educação devem ter em mente nesses novos tempos, ao trabalhar com seu público.
\end{abstract}

Palavras-chave: Media education, comunicação, educação, Itália.
Abstract: Gianna Cappello, President of the Italian Association of Education for Media and Communication (Associazione Italiana per l'Educazione ai Media e alla Comunicazione (MED)), talks about the increasing general interest in Media Education in the world - and about the priorities that the professionals involved in the fields of Communication and Education should have in mind nowadays when working with the public.

Keywords: Media Education, Communication, Education, Italy.

No ano de 2011, a Summer School of Media Education - evento realizado anualmente pela Associazione Italiana per l'Educazione ai Media e alla Comunicazione (MED), organização que reúne educadores e comunicadores por toda a Itália - completou 20 anos de existência. A data foi comemorada com a escolha, para tema do evento, do cinema e da experiência narrativa como poderosas ferramentas de comunicação contemporânea. As discussões a respeito da Media Education - definida pela associação como "uma atividade educativa e didática voltada a desenvolver nos jovens a informação e compreensão crítica acerca da natureza e da categoria dos meios, assim como das técnicas por eles empregadas para construir mensagens e produzir sentido, em gêneros e linguagens específicas - foram, porém, além: abordaram os diversos aspectos do desenvolvimento humano e educacional no mundo, o aumento do interesse de governos e da iniciativa privada pela interface entre comunicação e educação e quais os riscos e vantagens que isso representa para alunos, mestres e profissionais. Na entrevista a seguir, a presidente da MED, Gianna Capello, fala a respeito da realidade vivida por esses dois campos hoje, assim como sobre a importância dos

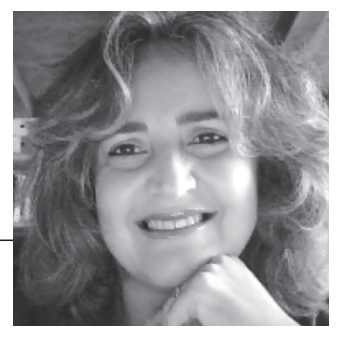

